\title{
Body size throughout the life-course and incident benign prostatic hyperplasia-related outcomes and nocturia
}

Saira Khan ${ }^{{ }^{*}{ }^{+}}$, K. Y. Wolin ${ }^{2+}$, R. Pakpahan ${ }^{3}$, R. L. Grubb ${ }^{4}$, G. A. Colditz ${ }^{3}$, L. Ragard ${ }^{5}$, J. Mabie ${ }^{6}$, B. N. Breyer ${ }^{7}$, G. L. Andriole ${ }^{8}$ and S. Sutcliffe ${ }^{3}$

\begin{abstract}
Background: Existing evidence suggests that there is an association between body size and prevalent Benign Prostatic Hyperplasia (BPH)-related outcomes and nocturia. However, there is limited evidence on the association between body size throughout the life-course and incident BPH-related outcomes.

Methods: Our study population consisted of men without histories of prostate cancer, BPH-related outcomes, or nocturia in the intervention arm of the Prostate, Lung, Colorectal, and Ovarian Cancer Screening Trial (PLCO) $(n=4710)$. Associations for body size in early- (age 20), mid- (age 50) and late-life (age $\geq 55$, mean age 60.7 years) and weight change with incident BPH-related outcomes (including self-reported nocturia and physician diagnosis of $\mathrm{BPH}$, digital rectal examination-estimated prostate volume $\geq 30 \mathrm{cc}$, and prostate-specific antigen [PSA] concentration > $1.4 \mathrm{ng} / \mathrm{mL}$ ) were examined using Poisson regression with robust variance estimation.

Results: Men who were obese in late-life were 25\% more likely to report nocturia (Relative Risk (RR): 1.25, 95\% Confidence Interval (Cl): 1.11-1.40; $p$-trend $\left.\mathrm{f}_{\text {for continuous BMI }}<0.0001\right)$ and men who were either overweight or obese in late-life were more likely to report a prostate volume $\geq 30 \mathrm{cc}\left(\mathrm{RR}_{\text {overweight }}: 1.13,95 \% \mathrm{Cl} 1.07-1.21 ; \mathrm{RR}\right.$ obese: $1.10,95 \% \mathrm{Cl}$ 1.02-1.19; p-trend $d_{\text {for continuous BMl }}=0.017$ ) as compared to normal weight men. Obesity at ages 20 and 50 was similarly associated with both nocturia and prostate volume $\geq 30 \mathrm{cc}$. Considering trajectories of body size, men who were normal weight at age 20 and became overweight or obese by later-life had increased risks of nocturia (RR normal to over-

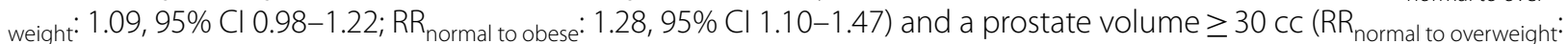
$1.12,95 \% \mathrm{Cl} 1.05-1.20)$. Too few men were obese early in life to examine the independent effect of early-life body size. Later-life body size modified the association between physical activity and nocturia.
\end{abstract}

Conclusions: We found that later-life body size, independent of early-life body size, was associated with adverse BPH outcomes, suggesting that interventions to reduce body size even late in life can potentially reduce the burden of BPH-related outcomes and nocturia.

Keywords: Benign Prostatic Hyperplasia (BPH), Body size, Obesity, Nocturia, Prostate volume, PLCO

*Correspondence: khans@udel.edu

tSaira Khan and K. Y. Wolin are co-first authors

1 Epidemiology Program, College of Health Sciences, University of Delaware, 100 Discovery Blvd., 7th floor, Newark, DE 19713, USA Full list of author information is available at the end of the article

\section{Introduction}

Benign prostatic hyperplasia (BPH)-related outcomes and lower urinary tract symptoms (LUTS) are extremely common among middle- and older-aged American men. By the time men reach their sixties approximately half are believed to have prevalent BPH/LUTS [1-3]. LUTS 
contribute to considerable bother and decreased quality of life among older men [4], and may lead to severe complications [5] as well as high healthcare costs [6].

Body size and obesity are risk factors for many inextricably linked conditions, including many sex-hormone related diseases, through a complex set of interrelated mechanisms. Specifically, recent interest in the role of body size in BPH/LUTS prevention has grown [7-9]. Greater body size, particularly obesity, may promote BPH/LUTS through several possible mechanisms. First, obesity increases the ratio of estrogens to testosterone and its metabolites, thus possibly exaggerating the natural increase that occurs with aging in men. This increase in the estrogen to testosterone ratio has been shown to contribute to $\mathrm{BPH}$ in dogs [10] and proposed to contribute to BPH/LUTS development in men. Second, obese individuals have higher levels of systemic inflammation and oxidative stress. Both systemic inflammation and oxidative stress have been proposed to promote unregulated prostate growth based on the frequent observation of inflammation in BPH tissue, and the observed correlation between the extent and severity of inflammation and the degree of prostate enlargement [11]. Finally, excess body weight may exert increased intra-abdominal pressure on the bladder and increased intravesical pressure, causing or exacerbating LUTS [12].

Consistent with these mechanisms, recent epidemiological reviews have observed positive associations between body mass index (BMI) and the presence of BPH and LUTS [13]. However, most of these studies did not exclude men with LUTS at baseline from their analyses. This approach is concerning because LUTS may cause men to alter their behaviors (e.g., reduce physical activity), which in turn may influence their BMI and contribute to misleading positive associations. Interestingly, fewer studies have investigated incident $\mathrm{BPH}$-related outcomes in men free of LUTS at baseline to avoid the concern of reverse causation. Findings from this smaller number of incident (rather than prevalent) studies have been variable [14-23].

As the underlying pathology of BPH/LUTS is believed to begin in men as early as their twenties or thirties [24], early-life body size may also potentially contribute to BPH/LUTS risk. However, only a few studies, to our knowledge, have investigated body size earlier in life or across the life-course in relation to BPH/LUTS $[10,17$, 23, 25-27], and most were limited to prevalent disease. Therefore, many of these early-life studies are still subject to the same methodologic concerns as described above for studies of later-life body size. Accurately assessing the relationship between earlier-life BMI and BPH/LUTS development is important to inform the necessary timing of future preventive interventions, i.e., whether body size reduction must be addressed earlier in life or whether a reduction in body size even later in life may still reduce $\mathrm{BPH} / \mathrm{LUTS}$ risk.

Finally, results from investigations of other disease outcomes have suggested that obesity and physical inactivity may act synergistically on disease processes [28]. Our previous analyses in this cohort found significant reductions in the incidence of some BPH-related outcomes for men who were physically active [29]. However, few studies have examined whether the benefits of physical activity are the same for obese and lean men.

We investigated the relationship between body size and risk of BPH-related outcomes and nocturia in the large Prostate, Lung, Colorectal, and Ovarian Cancer Screening Trial (PLCO). Importantly, this is one of the first studies to examine early-, mid-, and late-life body size, as well changes in body size throughout the life-course, with incident BPH/LUTS.

\section{Methods \\ Study population}

PLCO is a large, ongoing clinical trial designed to investigate the effects of prostate, lung, colorectal, and ovarian cancer screening on cancer-specific mortality [30]. From 1993 to 2001, men were recruited into PLCO at 10 screening centers across the U.S. Each site obtained IRB approval and consented participants. All men 55-74 years of age with no reported histories of prostate cancer or prostatectomy were eligible. Men who had used finasteride in the prior 6 months were not eligible. Half of recruited male participants were randomized to the intervention arm, which included annual prostatespecific antigen (PSA) testing for 5 years and digital rectal examinations (DREs) for 3 years after baseline, and half were randomized to the control arm, which consisted of routine medical care.

At baseline, participants in both arms of PLCO completed a baseline questionnaire, which included questions on weight history, height, and BPH/LUTS. Participants in the intervention arm also completed a food frequency and physical activity questionnaire. In 2004-2008, participants completed a supplemental questionnaire, which included additional questions about BPH/LUTS. Finally, from baseline until active data collection ended in 2015, participants completed brief annual questionnaires to update their cancer information and provide information on finasteride use.

We restricted our analysis to men in the intervention arm $(\mathrm{n}=38,340)$, as only these men provided complete baseline information on physical activity and diet, and underwent annual PSA tests and DREs. We also excluded participants with a history of cancer or evidence of BPHrelated outcomes at baseline, missing baseline data, or 
who did not complete the supplemental questionnaire. Detailed exclusion information is available in the Additional file 1 . These exclusion criteria resulted in an incident cohort of 4710 men. Because of the large number of excluded men, we also performed sensitivity analyses excluding only men with the BPH-related outcome of interest from the analysis (e.g., excluding only men with nocturia at baseline from the incident nocturia analysis). These analyses resulted in similar findings as the main analysis.

\section{Weight and physical activity assessment}

On the baseline questionnaire, participants reported their weight in pounds at ages 20,50, and currently (mean age at baseline $=60.7$ years), and their height in feet and inches. We used these values to calculate BMI at ages 20,50, and baseline, and weight change from ages 20 and 50 to baseline. BMI was categorized as underweight (<18.5), normal (18.5-24.9), overweight (25-29.9), or obese $(\geq 30)$. Because of small numbers, underweight and normal were combined for analysis. Weight change was categorized as weight loss $(>5 \mathrm{lb})$, weight maintenance (5 lb loss to $4 \mathrm{lb}$ gain), and increments of weight gain depending on the range of weight gain: 5-14, 15-24, 25-34, 35-44, 45-54, 55-64, 65-74, and $\geq 75$ lbs. Participants reported their current levels of "vigorous activities, such as swimming, brisk walking, etc." and categories of hours per week (none, $<1,1,2,3$, and $4+\mathrm{h} / \mathrm{wk}$ ) on the baseline questionnaire. We dichotomized physical activity as $\geq 1$ versus $<1 \mathrm{~h}$ per week.

\section{BPH-related outcomes and nocturia}

Methods used to define BPH-related outcomes are described in detail elsewhere [29, 31]. Briefly, the presence of BPH-related outcomes at baseline was determined using three items from the baseline questionnaire (waking during the night to urinate during the past year [nocturia]; a history of surgical procedures of the prostate, including transurethral resection of the prostate [TURP] and prostatectomy for benign disease; and a history of a physician diagnosis of "an enlarged prostate or benign prostatic hypertrophy"), DRE examinerestimated baseline prostate volume $\geq 30 \mathrm{cc}$, and baseline PSA $>1.4 \mathrm{ng} / \mathrm{mL}$ [32-35]. Additional details about baseline outcome definitions are noted in Table 1.

Incident BPH-related outcomes and nocturia were defined using data from the supplemental questionnaire, the annual study update questionnaires, and follow-up examinations (Table 1). Two sets of BPH-related questions were included on the supplemental questionnaire: average frequency of waking during the night to urinate in the past year and a physician diagnosis of an enlarged prostate or BPH. We used this information to define incident nocturia [32] and physician diagnosis of an enlarged

Table 1 Definitions of incident benign prostatic hyperplasia (BPH)-related outcomes and nocturia

\begin{tabular}{|c|c|c|c|c|c|}
\hline & Nocturia & $\begin{array}{l}\text { Physician } \\
\text { diagnosis }\end{array}$ & Finasteride use & $\begin{array}{l}\text { Prostate } \\
\text { volume } \geq 30 \mathrm{cc}\end{array}$ & PSA elevation \\
\hline \multicolumn{6}{|l|}{ Baseline questionnaire } \\
\hline $\begin{array}{l}\text { Wake } 2+\text { times/night to urinate during a typical night in the past year? (Noc- } \\
\text { turia) }\end{array}$ & $\times$ & $\times$ & $\times$ & $\times$ & $\times$ \\
\hline Ever been told by a doctor that they have an enlarged prostate or BPH? & $x$ & $\times$ & $\times$ & $\times$ & $\times$ \\
\hline Ever had TURP or prostatectomy for benign disease? & $\times$ & $\times$ & $\times$ & $\times$ & $\times$ \\
\hline \multicolumn{6}{|l|}{ Baseline examination } \\
\hline Prostate volume ${ }^{a} \geq 30 c c$ & $x$ & $\times$ & $\times$ & $\times$ & $\times$ \\
\hline PSA > $1.4 \mathrm{ng} / \mathrm{mL}$ and no known cancer & $\times$ & $\times$ & $\times$ & $\times$ & $\times$ \\
\hline \multicolumn{6}{|l|}{ Supplemental questionnaire } \\
\hline $\begin{array}{l}\text { Wake } 2+\text { times/night to urinate during a typical night in the past year? (Noc- } \\
\text { turia) }\end{array}$ & * & & & & \\
\hline Ever been told by a doctor that they have an enlarged prostate or BPH? & & * & & & \\
\hline \multicolumn{6}{|l|}{ Annual study update } \\
\hline Taken Proscar or Propecia (Finasteride) in the past year? & $\times$ & & * & $\times$ & $\times$ \\
\hline \multicolumn{6}{|l|}{ Follow-up examination } \\
\hline Prostate volume $e^{a} \geq 30$ cc on any of three DREs & & & & * & \\
\hline PSA $>1.4 \mathrm{ng} / \mathrm{mL}$ on any one of five PSA tests & & & & & * \\
\hline Total & 1515 & 1446 & 881 & 2499 & 1322 \\
\hline
\end{tabular}

$x=$ exclusion criteria; ${ }^{*}=$ inclusion criteria; $\mathrm{DRE}=$ digital rectal examination; $\mathrm{PSA}=$ prostate-specific antigen

a Calculated as $(\pi / 6) \times$ width $^{2} \times$ length, where width is the transverse measurement and length is the sagittal measurement. Both measurements were estimated by palpation by the trained DRE examiner 
prostate/BPH. Data from the annual study update questionnaires were used to define incident finasteride use, and data from the follow-up examinations were used to define incident prostate volume $\geq 30 \mathrm{cc}$ ), and incident PSA $>1.4 \mathrm{ng} / \mathrm{mL}$.

\section{Statistical analysis}

We investigated associations for body size with incident BPH-related outcomes and nocturia by calculating relative risks (RRs) using Poisson regression with robust variance estimation. All regression models included age. In addition, models for incident self-reported outcomes included time between the dates of completion of the baseline and supplemental questionnaires; those for incident prostate volume $\geq 30 \mathrm{cc}$ included number of follow-up DREs and time between participants' first and last DRE; and those for incident PSA elevation included number of follow-up PSA tests and time between participants' first and last PSA test. We investigated as potential confounders factors that might be associated with frequency of medical care including demographic factors, chronic medical conditions, physical activity, and suspected risk-factors for BPH-related outcomes including nutritional factors (see Table 2 for a complete list).

To investigate the possible influence of body size throughout the life-course on BPH/LUTS risk, we examined associations for (1) early-life (BMI at age 20), (2) mid-life (BMI at age 50), and (3) later-life (baseline BMI) with incident BPH-related outcomes. These analyses were not mutually adjusted for BMI at different ages, because the small number of men who lost weight over time resulted in small cell sizes and unstable models (Additional file 2: Figure S1).

To further examine associations for body size and weight change throughout the life-course, we investigated associations for weight change from (1) age 20 to baseline and (2) age 50 to baseline with incident $\mathrm{BPH}-$ related outcomes. Weight change throughout the lifecourse was examined in two ways. First, we examined the impact of changing BMI categories throughout the life-course (e.g., a man who went from the normal BMI category at age 20 to the overweight category at baseline compared to a man who remained normal weight throughout the life-course). Second, we examined the impact of smaller increments of weight change throughout the life-course (loss $>5$, loss or gain of 5, gain 5-14, gain $15-24$, gain $25-34$, gain $35-44$, gain $45-54$, gain $55-64$, gain $65-74$, gain $\geq 75 \mathrm{lbs}$ ) from both (1) age 20 to baseline and (2) age 50 to baseline. These models were adjusted for starting BMI at age 20 or 50 depending on the time interval examined (i.e., models examining weight change from age 20 to baseline were adjusted for BMI at age 20). In secondary analyses, we restricted the analysis to men who did not change BMI category over the time period of interest to further examine the influence of weight change independent of BMI category (i.e., smaller amounts of weight change insufficient to cause a change in BMI category).

To examine the joint influence of body size and physical activity, we performed analyses of baseline physical activity ( $<1 \mathrm{vs} . \geq 1 \mathrm{~h}$ of activity per week [29]) and incident BPH-related outcomes stratified by baseline BMI category.

\section{Results}

Of the 4710 men in the incident analysis, 1204 (25.6\%) participants were under/normal weight, 2399 (50.9\%) were overweight, and 1107 (23.5\%) were obese at baseline (Table 2). Compared to normal weight men, obese men tended to be younger, and were less likely to be Asian/ Pacific Islander, have a college degree or higher, be married, engage in physical activity $4 \mathrm{~h}$ /week, and be current smokers, although they were more likely to be former smokers. The most common comorbid chronic conditions were hypertension (26.7\%), arthritis (24.1\%), and coronary heart disease $(9.2 \%)$. Obese men were more likely to have hypertension, diabetes, arthritis, and gall bladder stone or inflammation as compared to normal weight men.

Considering BMI earlier in life, 3541 (75.2\%) participants were normal weight at age 20 and only $102(2.2 \%)$ were obese. At age 50, 1544 (32.8\%) participants were normal weight and $724(15.4 \%)$ were obese. Most participants gained weight over the course of their lives $(89.6 \%$ gained at least 5 lbs since age 20 with a mean weight gain of $35.9 \mathrm{lbs}$ among those who gained more than $5 \mathrm{lbs}$ ), and only a small percentage lost weight $(4.0 \%$ lost at least $5 \mathrm{lbs}$ since age 20 with a mean weight loss of $17.1 \mathrm{lbs}$ among those who lost more than $5 \mathrm{lbs}$ ).

Over the course of follow-up (median $=9$ years, range: 5-13), 1515 participants developed nocturia, 1446 reported a new physician diagnosis of $\mathrm{BPH}$, and 881 reported finasteride use (Table 1 ). With respect to outcomes measured at the follow-up examinations, 2499 men developed a prostate volume $\geq 30 \mathrm{cc}$ over a median of 4 years of follow-up (median number of follow-up DREs $=3$ ) and 1322 developed an elevated PSA over a median of 6 years of follow-up (median number of follow-up PSA tests $=5$ ).

\section{Later-life (baseline) BMI}

Baseline BMI was associated with several definitions of incident BPH-related outcomes (Table 3). Men who were obese were $25 \%$ more likely to report nocturia (RR: 1.25 , 95\% CI 1.11-1.40; p-trend for continuous BMI $<0.0001$ ) than normal weight men. Overweight and obese men were also 
Table 2 Age-adjusted baseline characteristics of 4710 male participants eligible for the analysis of body mass index and incident benign prostatic hyperplasia (BPH)-related outcomes and nocturia in the intervention arm of the Prostate, Lung, Colorectal, and Ovarian Cancer Screening Trial by baseline body mass index (BMI), 1993-2001

\begin{tabular}{|c|c|c|c|c|}
\hline & \multicolumn{3}{|c|}{ Baseline body mass index $\left(\mathrm{kg} / \mathrm{m}^{2}\right)$} & \multirow[t]{2}{*}{ All participants } \\
\hline & $<25$ & $25-29$ & $\geq 30$ & \\
\hline $\mathrm{N}$ & 1204 & 2399 & 1107 & 4710 \\
\hline Age (mean, years) & 61.1 & 60.8 & 60.2 & 60.7 \\
\hline \multicolumn{5}{|l|}{ Race/ethnicity (\%) } \\
\hline White & 88.3 & 92.2 & 92.9 & 91.3 \\
\hline Black & 2.0 & 1.3 & 3.0 & 1.9 \\
\hline Asian/Pacific Islander & 8.8 & 5.2 & 2.2 & 5.4 \\
\hline Other & 0.9 & 1.3 & 1.9 & 1.4 \\
\hline \multicolumn{5}{|l|}{ Education (\%) } \\
\hline Less than high school degree & 3.8 & 5.4 & 6.4 & 5.2 \\
\hline High school graduate & 12.3 & 18.4 & 21.6 & 17.6 \\
\hline Some college/post high school training & 28.3 & 32.5 & 36.2 & 32.3 \\
\hline College degree or higher & 55.6 & 43.8 & 35.9 & 44.9 \\
\hline \multicolumn{5}{|l|}{ Marital status (\%) } \\
\hline Married or living as married & 83.9 & 86.7 & 87.6 & 86.2 \\
\hline Not currently married & 16.1 & 13.3 & 12.4 & 13.8 \\
\hline \multicolumn{5}{|l|}{ Current physical activity (h/week, \%) } \\
\hline None & 11.0 & 12.4 & 18.3 & 13.4 \\
\hline One & 24.1 & 29.5 & 34.4 & 29.2 \\
\hline Two to three & 30.9 & 33.0 & 29.7 & 31.7 \\
\hline Four or more & 34.1 & 25.1 & 17.7 & 25.7 \\
\hline \multicolumn{5}{|l|}{ Smoking history (\%) } \\
\hline Never smoker & 34.4 & 29.1 & 24.1 & 29.3 \\
\hline Current cigarette smoker & 13.8 & 11.0 & 6.9 & 10.7 \\
\hline Former cigarette smoker & 45.3 & 51.5 & 60.3 & 52.0 \\
\hline Cigar or pipe smoker only & 6.5 & 8.3 & 8.8 & 8.0 \\
\hline \multicolumn{5}{|l|}{ Current mean intakes of } \\
\hline Energy (kcal/day) & 2255.0 & 2320.4 & 2445.4 & 2333.0 \\
\hline Carbohydrates (g/day) & 292.3 & 292.8 & 300.0 & 294.3 \\
\hline Fat (g/day) & 74.4 & 79.7 & 87.0 & 80.0 \\
\hline Poly-unsaturated fatty acid (g/day) & 15.2 & 15.9 & 17.0 & 16.0 \\
\hline Protein (g/day) & 85.7 & 90.7 & 97.9 & 91.1 \\
\hline Alcohol (g/day) & 18.0 & 17.1 & 17.1 & 17.3 \\
\hline Fruit (servings/day) & 2.5 & 2.3 & 2.3 & 2.3 \\
\hline Vegetables (servings/day) & 3.8 & 3.7 & 3.8 & 3.8 \\
\hline Red meat (g/day) & 87.5 & 102.3 & 124.3 & 103.7 \\
\hline \multicolumn{5}{|l|}{ Dietary } \\
\hline Alpha-carotene (mcg/day) & 1283.8 & 1280.5 & 1316.3 & 1289.8 \\
\hline Beta-carotene equivalents (mcg/day) & 5632.7 & 5566.4 & 5611.4 & 5593.9 \\
\hline Lycopene (mcg/day) & $11,205.0$ & $11,839.0$ & $12,667.0$ & $11,716.3$ \\
\hline \multicolumn{5}{|l|}{ Total (from the diet and supplements) } \\
\hline Beta-carotene (mcg/day) & 5463.9 & 5282.4 & 5276.2 & 5327.3 \\
\hline Selenium (mcg/day) & 117.6 & 122.1 & 130.3 & 122.9 \\
\hline Vitamin A (IU/day) & $15,230.0$ & $14,949.0$ & $14,987.0$ & $15,030.0$ \\
\hline Vitamin C (mg/day) & 441.8 & 418.8 & 377.6 & 415.0 \\
\hline Vitamin E (IU/day) & 164.7 & 153.3 & 152.5 & 156.0 \\
\hline Zinc (mg/day) & 20.3 & 20.3 & 21.0 & 20.5 \\
\hline
\end{tabular}


Table 2 (continued)

\begin{tabular}{|c|c|c|c|c|}
\hline & \multicolumn{3}{|c|}{ Baseline body mass index $\left(\mathrm{kg} / \mathrm{m}^{2}\right)$} & \multirow[t]{2}{*}{ All participants } \\
\hline & $<25$ & $25-29$ & $\geq 30$ & \\
\hline Multivitamin use (\%) & 48.8 & 42.7 & 39.5 & 43.5 \\
\hline \multicolumn{5}{|l|}{ Medical history (\%) } \\
\hline Hypertension & 15.8 & 26.9 & 38.1 & 26.7 \\
\hline Coronary heart disease & 6.8 & 9.4 & 11.5 & 9.2 \\
\hline Stroke & 1.0 & 1.0 & 1.6 & 1.2 \\
\hline Diabetes & 3.7 & 4.7 & 8.7 & 5.4 \\
\hline Arthritis & 19.1 & 23.5 & 30.8 & 24.1 \\
\hline Emphysema & 2.0 & 1.8 & 1.6 & 1.8 \\
\hline Bronchitis & 2.1 & 2.0 & 2.0 & 2.0 \\
\hline Gall bladder stone or inflammation & 3.4 & 5.6 & 9.0 & 5.8 \\
\hline Cirrhosis & 0.1 & 0.2 & 0.2 & 0.2 \\
\hline Diverticulosis & 3.7 & 4.3 & 4.1 & 4.1 \\
\hline Hepatitis & 3.5 & 3.5 & 3.1 & 3.4 \\
\hline Colon polyps and polyp syndromes & 6.8 & 6.6 & 8.1 & 7.0 \\
\hline Clinical prostatitis & 3.7 & 3.0 & 3.3 & 3.2 \\
\hline
\end{tabular}

g/day: grams per day; h/week: hour per week; IU/day: international unit per day; kcal/day: kilocalories per day; kg/m²: kilograms per meter²; mcg/day: micrograms per day; $\mathrm{mg} /$ day: milligrams per day

more likely to have a prostate volume $\geq 30 \mathrm{cc}\left(\mathrm{RR}_{\text {overweight }}\right.$ : 1.13, 95\% CI 1.07-1.21; RR $\mathrm{R}_{\text {obese }}: 1.10$, 95\% CI 1.02-1.19; p-trend $\left.\mathrm{f}_{\text {for continuous } \mathrm{BMI}}=0.017\right)$. However, men who were overweight or obese were less likely to have an elevated PSA ( $\mathrm{RR}_{\text {overweight: }}: 0.89,95 \%$ CI $0.80-0.99 ; \mathrm{RR}_{\text {obese }}: 0.75$, 95\% CI 0.65-0.85; p-trend $\mathrm{d}_{\text {for continuous BMI }}<0.0001$ ), and no more likely to report a physician diagnosis of an enlarged prostate/BPH than normal weight men. Associations for finasteride use were difficult to interpret because of the small number of men who used finasteride, but they tended to be consistent in direction and magnitude to associations for nocturia and a prostate volume $\geq 30 \mathrm{cc}$. Adjusting for covariates did not change any of the associations. However, it is important to note that these findings are not independent of BMI in early- or mid-life (i.e., BMI at ages 20 and 50).

\section{Early- and mid-life BMI}

Similar to the results for baseline BMI, BMI at age 20 was associated with an increased risk of BPH-related outcomes (Table 3). Obese men were $20 \%$ more likely to develop nocturia $(R R=1.20,95 \%$ CI $0.93-1.55$; p-trend $=0.026)$ and $21 \%$ more likely to develop a prostate volume $\geq 30$ cc $(\mathrm{RR}=1.2195 \%$ CI 1.05-1.39; p-trend $=0.0006)$. Results for BMI at age 50 were similar to those for BMI at age 20 with significant findings for nocturia $\left(\mathrm{RR}_{\text {obese }}=1.18,95 \% \mathrm{CI} 1.04-1.34\right.$; p-trend $=0.0021)$ and a prostate volume $\geq 30 \quad$ cc $\left(\mathrm{RR}_{\text {obese }}=1.11,95 \%\right.$ CI 1.02-1.20; p-trend $\left.=0.0048\right)$.

\section{BMI across the life-course}

As our findings for BMI at specific ages (i.e., age 20, age 50 , and baseline) might reflect the fact that men who are overweight or obese as young men tend to remain overweight or obese throughout life, we next sought to determine the independent effects of BMI at different ages on risk of $\mathrm{BPH}$-related outcomes. This is important to determine the necessary timing of future prevention interventions. Compared to men who remained normal weight throughout life, those who were normal weight at age 20 and became overweight by baseline had slightly increased risks of nocturia ( $R R=1.09,95 \%$ CI $0.98-1.22)$ and a prostate volume $\geq 30 \mathrm{cc}(\mathrm{RR}=1.12,95 \% \mathrm{CI} 1.05-1.20)$ and those who were normal weight at age 20 and became obese had an increased risk of nocturia ( $R R=1.28,95 \%$ CI 1.10-1.47, Table 4). Men who were overweight at age 20 who became obese also had an increased risk of nocturia relative to those who remained overweight throughout life $(R R=1.49,95 \%$ CI $1.00-2.21)$. Generally similar findings were observed for cross-categories of BMI at age 50 and baseline BMI. Together, these findings suggest that later-life overweight and obesity (i.e., at $\geq 55$ years of age, the minimum age of entry into PLCO) contributes independently, of early-life body size, to nocturia, and that later-life overweight contributes independently to a prostate volume $\geq 30 \mathrm{cc}$.

Too few men were overweight or obese in early-life and too few men lost large amounts of weight through the life-course to investigate the independent effects of earlylife overweight and obesity with confidence. 
Table 3 Age-adjusted risk ratios (RRs) and 95\% confidence intervals (Cls) of incident benign prostatic hyperplasia (BPH)-related outcomes and nocturia by body mass index (BMI) across the life-course; Prostate, Lung, Colorectal, and Ovarian Cancer Screening Trial

\begin{tabular}{|c|c|c|c|c|c|c|c|}
\hline \multicolumn{2}{|c|}{$<25$} & \multicolumn{2}{|c|}{$25-29$} & \multicolumn{2}{|c|}{$\geq 30$} & Per $5 \mathrm{~kg} / \mathrm{m}^{2}$ increase & \multirow[t]{2}{*}{ p-trend ${ }^{a}$} \\
\hline RR & $95 \% \mathrm{Cl}$ & RR & $95 \% \mathrm{Cl}$ & $\mathrm{RR}$ & $95 \% \mathrm{Cl}$ & RR & \\
\hline
\end{tabular}

\begin{tabular}{|c|c|c|c|c|c|c|c|c|c|}
\hline \multicolumn{10}{|l|}{ Baseline BMI } \\
\hline Nocturiab $^{b}$ & 1.00 & Referent & 1.07 & $0.96,1.18$ & 1.25 & $1.11,1.40$ & 1.11 & $1.06,1.16$ & $<0.0001$ \\
\hline No. of cases & 363 & & 763 & & 389 & & & & \\
\hline Physician Diagnosis ${ }^{b}$ & 1.00 & Referent & 1.00 & $0.90,1.11$ & 0.95 & $0.84,1.07$ & 0.97 & $0.92,1.02$ & 0.26 \\
\hline No. of cases & 377 & & 748 & & 321 & & & & \\
\hline Finasteride $^{b}$ & 1.00 & Referent & 1.07 & $0.71,1.61$ & 1.44 & $0.91,2.27$ & 1.17 & $0.96,1.42$ & 0.11 \\
\hline No. of cases & 32 & & 67 & & 40 & & & & \\
\hline Prostate volume $\geq 30 c c^{c}$ & 1.00 & Referent & 1.13 & $1.07,1.21$ & 1.10 & $1.02,1.19$ & 1.04 & $1.01,1.07$ & 0.017 \\
\hline No. of cases & 604 & & 1351 & & 544 & & & & \\
\hline Elevated PSA ${ }^{d}$ & 1.00 & Referent & 0.89 & $0.80,0.99$ & 0.75 & $0.65,0.85$ & 0.86 & $0.81,0.92$ & $<0.0001$ \\
\hline No. of cases & 381 & & 682 & & 259 & & & & \\
\hline \multicolumn{10}{|l|}{ BMl at age 20} \\
\hline Nocturia $^{b}$ & 1.00 & Referent & 1.09 & $0.99,1.20$ & 1.20 & $0.93,1.55$ & 1.08 & $1.01,1.16$ & 0.026 \\
\hline No. of cases & 1124 & & 353 & & 38 & & & & \\
\hline Physician diagnosis ${ }^{b}$ & 1.00 & Referent & 0.98 & $0.88,1.09$ & 0.88 & $0.64,1.22$ & 0.98 & $0.91,1.05$ & 0.57 \\
\hline No. of cases & 1098 & & 320 & & 28 & & & & \\
\hline Finasteride $^{b}$ & 1.00 & Referent & 1.18 & $0.81,1.71$ & e & & 1.09 & $0.86,1.39$ & 0.49 \\
\hline No. of cases & 103 & & 35 & & & & & & \\
\hline Prostate volume $\geq 30 \mathrm{cc}^{c}$ & 1.00 & Referent & 1.05 & $0.99,1.11$ & 1.21 & $1.05,1.39$ & 1.07 & $1.03,1.12$ & 0.0006 \\
\hline No. of cases & 1871 & & 566 & & 62 & & & & \\
\hline Elevated PSA ${ }^{d}$ & 1.00 & Referent & 0.98 & $0.88,1.10$ & 0.70 & $0.47,1.04$ & 0.93 & $0.86,1.01$ & 0.074 \\
\hline No. of cases & 1006 & & 296 & & 20 & & & & \\
\hline \multicolumn{10}{|l|}{ BMl at age 50} \\
\hline Nocturiab $^{b}$ & 1.00 & Referent & 1.07 & $0.98,1.18$ & 1.18 & $1.04,1.34$ & 1.09 & $1.03,1.15$ & 0.0021 \\
\hline No. of cases & 480 & & 794 & & 241 & & & & \\
\hline Physician diagnosis ${ }^{b}$ & 1.00 & Referent & 0.92 & $0.84,1.01$ & 0.92 & $0.80,1.05$ & 0.95 & $0.93,1.01$ & 0.13 \\
\hline No. of cases & 504 & & 730 & & 212 & & & & \\
\hline Finasteride $^{b}$ & 1.00 & Referent & 1.07 & $0.73,1.57$ & 1.49 & $0.93,2.41$ & 1.18 & $0.96,1.46$ & 0.12 \\
\hline No. of cases & 42 & & 70 & & 27 & & & & \\
\hline Prostate volume $\geq 30 \mathrm{cc}^{c}$ & 1.00 & Referent & 1.08 & $1.02,1.15$ & 1.11 & $1.02,1.20$ & 1.05 & $1.02,1.09$ & 0.0048 \\
\hline No. of cases & 796 & & 1341 & & 362 & & & & \\
\hline Elevated PSA ${ }^{d}$ & 1.00 & Referent & 0.91 & $0.82,1.00$ & 0.75 & $0.64,0.89$ & 0.85 & $0.79,0.90$ & $<0.0001$ \\
\hline No. of cases & 476 & & 682 & & 164 & & & & \\
\hline
\end{tabular}

BPH: benign prostatic hyperplasia; Cl: Confidence Interval; BMI: body mass index; RR: risk ratio

a For continuous BMI

b Also adjusted for time between completion of the baseline and supplemental questionnaires

c Also adjusted for number of DREs and time between participants' first and last DRE

d Also adjusted for number of PSA tests and time between participants' first and last PSA test

e Too few cases $(n=1)$ to estimate

\section{Incremental and within BMI category weight change across the life-course}

Findings for weight change from ages 20 and 50 (Table 5) were consistent with those from the BMI cross-category analyses. For weight change from age 20 to baseline, risk of nocturia increased slightly for a 35-44 lb weight gain and increased to a greater degree for $\mathrm{a} \geq 45 \mathrm{lb}$ gain; smaller amounts of weight gain, particularly those insufficient to cause an increase in BMI category, were not associated with increased nocturia risk. Weight gain sufficient to cause a change in BMI category was also necessary to increase risk of a prostate volume $\geq 30 \mathrm{cc}$. Similar findings were observed for weight change from age 50 to baseline as for weight change from age 20 to baseline. 
Table 4 Age-adjusted risk ratios (RRs) and 95\% confidence intervals (Cls) of incident benign prostatic hyperplasia (BPH)-related outcomes and nocturia by body mass index (BMI) change across the life-course; Prostate, Lung, Colorectal, and Ovarian Cancer Screening Trial

\begin{tabular}{|c|c|c|c|c|c|c|c|}
\hline & & Base & $\left(\mathrm{kg} / \mathrm{m}^{2}\right)$ & & & & \\
\hline & & $<25$ & & $25-29$ & & $\geq 30$ & \\
\hline & & $\mathrm{RR}$ & $95 \% \mathrm{Cl}$ & RR & $95 \% \mathrm{Cl}$ & $\mathrm{RR}$ & $95 \% \mathrm{Cl}$ \\
\hline BMI at & & & & & & & \\
\hline$<25$ & Nocturia $^{a}$ & 1.00 & Referent & 1.09 & $0.98,1.22$ & 1.28 & $1.10,1.47$ \\
\hline & No. of cases & 336 & & 609 & & 179 & \\
\hline & Prostate volume $\geq 30 \mathrm{cc}^{\mathrm{b}}$ & 1.00 & Referent & 1.12 & $1.05,1.20$ & 1.04 & $0.94,1.15$ \\
\hline & No. of cases & 572 & & 1058 & & 241 & \\
\hline $25-29$ & Nocturia $^{a}$ & 1.40 & $1.03,1.90$ & 1.09 & $0.93,1.28$ & 1.25 & $1.08,1.45$ \\
\hline & No. of cases & 26 & & 150 & & 177 & \\
\hline & Prostate volume $\geq 30 \mathrm{cc}^{\mathrm{b}}$ & 0.94 & $0.73,1.20$ & 1.16 & $1.06,1.26$ & 1.10 & $1.00,1.21$ \\
\hline & No. of cases & 31 & & 280 & & 255 & \\
\hline$\geq 30$ & Nocturia $^{a}$ & c & & c & & 1.41 & $1.07,1.86$ \\
\hline & No. of cases & & & & & 33 & \\
\hline & Prostate volume $\geq 30 \mathrm{cc}^{\mathrm{b}}$ & c & & 1.61 & $1.32,1.97$ & 1.25 & $1.05,1.48$ \\
\hline & No. of cases & & & 13 & & 48 & \\
\hline BMI at & & & & & & & \\
\hline$<25$ & Nocturia $^{a}$ & 1.00 & Referent & 1.09 & $0.93,1.28$ & c & \\
\hline & No. of cases & 317 & & 158 & & & \\
\hline & Prostate volume $\geq 30 \mathrm{cc}^{b}$ & 1.00 & Referent & 1.07 & $0.98,1.18$ & c & \\
\hline & No. of cases & 539 & & 253 & & & \\
\hline $25-29$ & Nocturia $^{a}$ & 1.04 & $0.80,1.34$ & 1.06 & $0.94,1.19$ & 1.30 & $1.13,1.49$ \\
\hline & No. of cases & 44 & & 561 & & 189 & \\
\hline & Prostate volume $\geq 30 \mathrm{cc}^{b}$ & 0.87 & $0.72,1.05$ & 1.13 & $1.06,1.21$ & 1.06 & $0.96,1.17$ \\
\hline & No. of cases & 60 & & 1029 & & 252 & \\
\hline$\geq 30$ & Nocturia $^{a}$ & c & & 1.23 & $0.96,1.58$ & 1.21 & $1.05,1.41$ \\
\hline & No. of cases & & & 44 & & 195 & \\
\hline & Prostate volume $\geq 30 \mathrm{cc}^{\mathrm{b}}$ & c & & 1.16 & $1.00,1.36$ & 1.10 & $1.00,1.21$ \\
\hline & No. of cases & & & 69 & & 288 & \\
\hline
\end{tabular}

BPH: benign prostatic hyperplasia; Cl: Confidence Interval; BMI: body mass index; RR: risk ratio

a Also adjusted for time between completion of the baseline and supplemental questionnaires

b Also adjusted for number of DREs and time between participants' first and last DRE

c Too few cases $(n \leq 5)$ to estimate

Weight loss did not appear to be protective for either nocturia or a prostate volume $\geq 30 \mathrm{cc}$, but the amount of weight loss in the cohort was small.

\section{Physical activity and BMI}

Physical activity was not associated with nocturia risk among obese men ( $R R=0.94,95 \%$ CI $0.80-1.10)$, but was associated with a reduced risk of nocturia among overweight men ( $R R=0.85,95 \%$ CI $0.75-0.96)$. Normal weight men had a non-significant risk reduction similar to that of overweight men ( $R R=0.86,95 \% \mathrm{CI} 0.71-1.04)$. No associations were observed for physical activity and a prostate volume $\geq 30 \mathrm{cc}$ in normal weight, overweight, or obese men $(\mathrm{RRs}=0.99-1.04)$.

\section{Discussion}

This report expands on previous research on body size and $\mathrm{BPH}$ by examining body size in relation to incident, as opposed to prevalent, BPH-related outcomes and nocturia, and by examining body size across the life-course as opposed to later in life only. Our findings suggest that greater later-life body size (overweight or obesity) is associated with adverse BPH-related outcomes, independent of early-life body size. Specifically, becoming overweight or obese, but not gaining smaller amounts of weight 





throughout the life-course, was associated with increased risks of nocturia and a prostate volume $\geq 30 \mathrm{cc}$. This is important as it suggests that interventions to reduce overweight or obesity even later in life have the potential to prevent adverse BPH-related outcomes. Too few men were obese early in life or lost large amounts of weight to determine the independent effects of greater earlylife body size. While rare in PLCO, early-life obesity will become important to understand with the growing obesity epidemic. Finally, although we found that engaging in physical activity reduced the risk of nocturia for normal and overweight men, it did not reduce the risk for obese men or the risk of a prostate volume $\geq 30 \mathrm{cc}$ for men of any weight, suggesting the need for other prevention strategies.

\section{Later-life body size}

Our results for later-life body size are generally consistent with the literature to date, including two meta-analyses $[8,9]$. Although a strength of our study is that we specifically examined incident $\mathrm{BPH}$, our findings were generally consistent with those that examined prevalent BPH. Our positive findings for nocturia are similar to those from most existing studies of body size and incident $\mathrm{BPH}$ or LUTS (or composite endpoints including LUTS, which likely dominated these endpoints) $[8,15,17,20,21,36]$. Our findings for a prostate volume $\geq 30 \mathrm{cc}$ are also similar to those from most previous studies of prevalent large prostate volume/weight, as well as to those that examined prostate growth over time. [8, 9, 11, 13, 36-42]. In addition, although our findings for finasteride use were not statistically significant, they are still consistent in direction and magnitude to those from most previous studies of incident BPH/LUTS and prevalent prostate volume. Finally, our protective findings for overweight/ obesity and an elevated PSA are similar to those from many previous studies [43-46], and likely reflect the influence of overweight/obesity on blood volume rather than on prostate size.

Despite the similarity of our findings to those from many previous studies, they do still differ from a handful of previous studies $[14,16,19,23,47]$. These differences could be partly attributed to differences in patient populations (e.g., Asian versus North American populations); variations in ages of BMI ascertainment (e.g., mid- versus late-life), inconsistencies in both exposure and outcome definitions (e.g., continuous versus categories of BMI, varying composite definitions of $\mathrm{BPH}$, outcomes ascertained by ICD-9 codes versus self-report, and changes in clinical practice over the decades captured by these studies). In addition, our null results for a physician diagnosis of BPH differ from our positive or suggestively positive findings for nocturia and finasteride use. This difference may possibly be explained by the more stringent criteria required for a physician diagnosis rather than self-report of LUTS.

\section{Body size through the life-course}

Despite growing interest in a life-course approach to disease causation, few studies have examined how early-life factors or changes in risk factors may alter risk of $\mathrm{BPH}$ related outcomes. This information is critical for chronic conditions as it provides key information on when interventions should be targeted. In our analyses, we found a clear association between gaining large amounts of weight (at least $45 \mathrm{lbs}$ ) and risk of nocturia, similar to findings from one [17], but not another [23] study of weight change and incident BPH-related outcomes. Specifically, in the study by Mondul et al., weight gain from age 21 was significantly associated with risk of moderate or worse LUTS only among men who gained at least 40 lbs, and with progression to severe LUTS among those who gained at least 30 lbs [17]. By contrast, Gupta et al., did not observe an association between weight change per decade (mean weight change per decade $4-5 \mathrm{~kg}$ ) and the development of BPH [23]. Together, these findings suggest that a sizeable weight gain of at least 30-40 lbs throughout the life-course is needed before the risk for LUTS increases.

Despite the large sample size of PLCO, one limitation in this analysis is that too few men were obese early in life and too few lost weight to inform: (1) the independent contribution of early-life body size on the risks of nocturia and a large prostate, and (2) weight loss as a possible prevention strategy for BPH/LUTS. Cohorts with greater prevalences of early-life obesity, such as more contemporary cohorts, and cohorts with greater prevalences of weight loss will be required to answer these questions. All that we can say with a greater degree of certainty from our analyses is that being overweight or obese as an older man was associated with increased risks of developing nocturia and a prostate volume $\geq 30 \mathrm{cc}$.

\section{Physical activity}

Because previous studies have indicated a role for physical activity in BPH/LUTS [29], we examined the joint association of activity and obesity. Our findings suggest that the physical activity benefit may be limited to normal and overweight men, and that among obese men, the effects of obesity trump any potential benefit of physical activity. This finding, which is consistent with that observed in the Southern Community Study [20], is unfortunate because other management strategies and therapies, such as finasteride, have also had limited efficacy in obese men $[40,48]$. 
Our study results must be interpreted in light of some limitations. First, it is difficult to accurately measure prostate volume, particularly in obese men [43]. This could have contributed to our weaker dose-response for increasing BMI with risk of DRE-estimated prostate volume $\geq 30 \mathrm{cc}$ than for nocturia. In addition, weight was based on self-report and men were asked to recall their weight decades earlier. However, despite this, we were still able to observe significant associations between both early- and mid-life BMI and BPH/LUTS, as well as between weight gain and BPH/LUTS. Previous research has shown that middle-aged men can accurately recall both height and weight 27-37 years later, and, on average, weight gain is only underestimated by $3 \mathrm{~kg}$ and BMI by $1 \mathrm{~kg} / \mathrm{m}^{2}$ [49]. It is also important to note that BMI may be a less accurate measure of obesity in younger, muscular men, as it does not distinguish between muscle mass and body fat [50]. Moreover, unmeasured components of medical history, including use of certain medications such as diuretics, could have biased our results. Unmeasured medical conditions could have also impacted our findings, however, our assessment of common comorbidities (see Table 2 for full list) including diabetes, indicated that they were not significant confounders. Finally, our measure of BPH-related outcomes only included one LUTS-nocturia. Thus, men with LUTS other than nocturia, particularly milder storage LUTS (e.g., urinary urgency and frequency) that would be unlikely to contribute to a physician diagnosis of $\mathrm{BPH}$ or finasteride use, may not have been captured by our BPH-related outcome definitions.

Despite these limitations, our study has several strengths. These include ascertaining incident rather than prevalent BPH/LUTS, and measuring BMI at multiple-time points including early-, mid-, and later-life.

\section{Conclusion}

We found that obesity was associated with incident nocturia and a prostate volume $\geq 30 \mathrm{cc}$. Importantly, we were able to show that late-life BMI was associated with risk of BPH/LUTS independent of early-life BMI, indicating that interventions later in life have the potential to reduce $\mathrm{BPH} / \mathrm{LUTS}$. Our results further suggest that nocturia may be prevented or reduced through weight management, but that exercise alone may not be as effective in reducing nocturia risk in obese men.

\footnotetext{
Abbreviations

BPH: Benign Prostatic Hyperplasia; PLCO: Prostate, Lung, Colorectal, and Ovarian Cancer Screening Trial; RR: Relative Risk; Cl: Confidence Interval; LUTS: Lower Urinary Tract Symptoms; DRE: Digital Rectal Exam; TURP: Transurethral Resection of the Prostate; PSA: Prostate Specific Antigen; BMI: Body Mass Index.
}

\section{Supplementary Information}

The online version contains supplementary material available at https://doi. org/10.1186/s12894-021-00816-5.

Additional file 1. Study exclusion criteria.

Additional file 2: Supporting Figure 1. Average weight change in pounds from ages 20 and 50 to baseline, by BMI Category.

\section{Authors' contributions}

KYW and SS contributed to the conception and design. RP conducted the data analysis. SK, RLG, GAC, JM, BNB, and GLA made substantial contributions to interpreting data and drafting manuscript. All authors read and approved the final manuscript.

\section{Funding}

This project was supported by the National Institute of Diabetes and Digestive and Kidney Diseases: R21DK090595. SK was supported by Department of Defense (PC170130; PI, Khan). SS was supported by Barnes-Jewish Hospital Foundation, the Alvin J. Siteman Cancer Center (NIH/NCI (P30 CA091842)), and the Institute for Clinical and Translational Sciences (NIH/NCATS (UL1 TR002345)).

\section{Data sharing and data accessibility}

PLCO data is available to the general scientific community: https://cdas.cancer. gov/learn/plco/instructions/?type=data.

\section{Declarations}

\section{Ethics approval and consent to participate}

This study was reviewed by the Human Subjects Protection Office at Washington University and was found not to constitute human subjects research and determined to be HIPPA exempt (\#10-0037).

\section{Competing interests}

KYW reports personal fees from Coeus Health and Circea, outside the submitted work; in addition, she has a patent pending for a digital weight management platform. All other authors declare they have no conflict of interest.

\section{Author details}

${ }^{1}$ Epidemiology Program, College of Health Sciences, University of Delaware, 100 Discovery Blvd., 7th floor, Newark, DE 19713, USA. ${ }^{2}$ Coeus Health, 222 W Merchandise Mart Plaza, Chicago, IL 60654, USA. ${ }^{3}$ Division of Public Health Sciences, Department of Surgery, Washington University in St. Louis School of Medicine, 660 S. Euclid Ave., Campus Box 8100, St. Louis, MO 63110, USA. ${ }^{4}$ Department of Urology, Medical University of South Carolina, 135 Rutledge Ave, Charleston, SC 29425, USA. ${ }^{5}$ Westat, 1600 Research Blvd, Rockville, MD 20850, USA. ${ }^{6}$ Information Management Services, Inc., 1455 Research Blvd, Suite 315 , Rockville, MD 20850, USA. ${ }^{7}$ Departments of Urology and Epidemiology and Biostatistics, University of California - San Francisco, 400 Parnassus Ave \# 610, San Francisco, CA 94143, USA. ${ }^{8}$ Division of Urologic Surgery, Department of Surgery, Washington University in St. Louis School of Medicine, 4921 Parkway Place, St. Louis, MO 63110, USA.

Received: 7 November 2020 Accepted: 15 March 2021

Published online: 27 March 2021

\section{References}

1. Chute CG, Panser LA, Girman CJ, Oesterling JE, Guess HA, Jacobsen SJ, et al. The prevalence of prostatism: a population-based survey of urinary symptoms. J Urol. 1993;150(1):85-9.

2. Wei JT, Schottenfeld D, Cooper K, Taylor JM, Faerber GJ, Velarde MA, et al. The natural history of lower urinary tract symptoms in black American men: relationships with aging, prostate size, flow rate and bothersomeness. J Urol. 2001;165(5):1521-5. 
3. Coyne KS, Sexton CC, Thompson CL, Milsom I, Irwin D, Kopp ZS, et al. The prevalence of lower urinary tract symptoms (LUTS) in the USA, the UK and Sweden: results from the epidemiology of LUTS (EpiLUTS) study. BJU Int. 2009;104(3):352-60.

4. Girman CJ, Jacobsen SJ, Tsukamoto T, Richard F, Garraway WM, Sagnier $\mathrm{PP}$, et al. Health-related quality of life associated with lower urinary tract symptoms in four countries. Urology. 1998;51(3):428-36.

5. Roehrborn CG, McConnell JD. Benign prostatic hyperplasia: etiology, pathophysiology, epidemiology, and natural history. Campbell Walsh Urol. 2007;10:2649-73

6. Wei JT, Calhoun E, Jacobsen SJ. Urologic diseases in America project: benign prostatic hyperplasia. J Urol. 2005;173(4):1256-61.

7. Gacci M, Corona G, Vignozzi L, Salvi M, Serni S, De Nunzio C, et al. Metabolic syndrome and benign prostatic enlargement: a systematic review and meta-analysis. BJU Int. 2015;115(1):24-31.

8. Vignozzi L, Gacci M, Maggi M. Lower urinary tract symptoms, benign prostatic hyperplasia and metabolic syndrome. Nat Rev Urol. 2016:13(2):108-19.

9. Wang $S$, Mao Q, Lin Y, Wu J, Wang X, Zheng $X$, et al. Body mass index and risk of BPH: a meta-analysis. Prostate Cancer Prostatic Dis. 2012;15(3):265-72.

10. Giovannucci E, Rimm EB, Chute CG, Kawachi I, Colditz GA, Stampfer $\mathrm{MJ}$, et al. Obesity and benign prostatic hyperplasia. Am J Epidemiol. 1994;140(11):989-1002.

11. Parsons JK, Carter HB, Partin AW, Windham BG, Metter EJ, Ferrucci L, et al. Metabolic factors associated with benign prostatic hyperplasia. J Clin Endocrinol Metab. 2006;91(7):2562-8.

12. Cohen PG. Abdominal obesity and intra-abdominal pressure: a new paradigm for the pathogenesis of the hypogonadal-obesity-BPH-LUTS connection. Horm Mol Biol Clin Investig. 2012;11(1):317-20.

13. Parsons JK, Sarma AV, McVary K, Wei JT. Obesity and benign prostatic hyperplasia: clinical connections, emerging etiological paradigms and future directions. J Urol. 2013;189(1 Suppl):S102-6.

14. Glynn RJ, Campion EW, Bouchard GR, Silbert JE. The development of benign prostatic hyperplasia among volunteers in the Normative Aging Study. Am J Epidemiol. 1985;121(1):78-90.

15. Kristal AR, Arnold KB, Schenk JM, Neuhouser ML, Weiss N, Goodman P, et al. Race/ethnicity, obesity, health related behaviors and the risk of symptomatic benign prostatic hyperplasia: results from the prostate cancer prevention trial. J Urol. 2007;177(4):1395-400.

16. Kok ET, Schouten BW, Bohnen AM, Groeneveld FP, Thomas S, Bosch $\mathrm{JL}$. Risk factors for lower urinary tract symptoms suggestive of benign prostatic hyperplasia in a community based population of healthy aging men: the Krimpen Study. J Urol. 2009;181(2):710-6.

17. Mondul AM, Giovannucci E, Platz EA. A prospective study of obesity, and the incidence and progression of lower urinary tract symptoms. J Urol. 2014;191(3):715-21.

18. Parsons JK, Messer K, White M, Barrett-Connor E, Bauer DC, Marshall LM. Obesity increases and physical activity decreases lower urinary tract symptom risk in older men: the Osteoporotic Fractures in Men study. Eur Urol. 2011;60(6):1173-80.

19. Wong SY, Woo J, Leung JC, Leung PC. Depressive symptoms and lifestyle factors as risk factors of lower urinary tract symptoms in Southern Chinese men: a prospective study. Aging Male. 2010;13(2):113-9.

20. Penson DF, Munro HM, Signorello LB, Blot WJ, Fowke JH. Obesity, physical activity and lower urinary tract symptoms: results from the Southern Community Cohort Study. J Urol. 2011;186(6):2316-22.

21. Zhao SC, Xia M, Tang JC, Yan Y. Associations between metabolic syndrome and clinical benign prostatic hyperplasia in a northern urban Han Chinese population: a prospective cohort study. Sci Rep. 2016;6:33933.

22. Jung JH, Ahn SV, Song JM, Chang SJ, Kim KJ, Kwon SW, et al. Obesity as a risk factor for prostatic enlargement: a retrospective cohort study in Korea. Int Neurourol J. 2016;20(4):321-8.

23. Gupta A, Gupta S, Pavuk M, Roehrborn CG. Anthropometric and metabolic factors and risk of benign prostatic hyperplasia: a prospective cohort study of Air Force veterans. Urology. 2006:68(6):1198-205.

24. Berry SJ, Coffey DS, Walsh PC, Ewing LL. The development of human benign prostatic hyperplasia with age. J Urol. 1984;132(3):474-9.

25. Rohrmann S, Smit E, Giovannucci E, Platz EA. Associations of obesity with lower urinary tract symptoms and noncancer prostate surgery in the
Third National Health and Nutrition Examination Survey. Am J Epidemiol. 2004;159(4):390-7.

26. Fritschi L, Tabrizi J, Leavy J, Ambrosini G, Timperio A. Risk factors for surgically treated benign prostatic hyperplasia in Western Australia. Public Health. 2007;121(10):781-9.

27. Zucchetto A, Tavani A, Dal Maso L, Gallus S, Negri E, Talamini R, et al. History of weight and obesity through life and risk of benign prostatic hyperplasia. IJO. 2005;29(7):798-803.

28. Lee CD, Jackson AS, Blair SN. US weight quidelines: is it also important to consider cardiorespiratory fitness? Int J Obes Relat Metab Disord. 1998;22(Suppl 2):S2-7.

29. Wolin KY, Grubb RL III, Pakpahan R, Ragard LR, Mabie J, Andriole G, et al. Physical activity and benign prostatic hyperplasia-related outcomes and nocturia. Med Sci Sports Exerc. 2015:47(3):581-92.

30. Prorok PC, Andriole GL, Bresalier RS, Buys SS, Chia D, Crawford ED, et al. Design of the Prostate, Lung, Colorectal and Ovarian (PLCO) cancer screening trial. Control Clin Trials. 2000;21 (6 Suppl):273S-309S.

31. Sutcliffe S, Grubb lii RL, Platz EA, Ragard LR, Riley TL, Kazin SS, et al. Non-steroidal anti-inflammatory drug use and the risk of benign prostatic hyperplasia-related outcomes and nocturia in the Prostate, Lung, Colorectal, and Ovarian Cancer Screening Trial. BJU Int. 2012;110(7):1050-9.

32. Abrams P, Swift S. Solifenacin is effective for the treatment of OAB dry patients: a pooled analysis. Eur Urol. 2005:48(3):483-7.

33. Jacobsen SJ, Jacobson DJ, Girman CJ, Roberts RO, Rhodes T, Guess HA, et al. Treatment for benign prostatic hyperplasia among community dwelling men: the Olmsted County study of urinary symptoms and health status. J Urol. 1999;162(4):1301-6.

34. Pinsky PF, Kramer BS, Crawford ED, Grubb RL, Urban DA, Andriole GL, et al. Prostate volume and prostate-specific antigen levels in men enrolled in a large screening trial. Urology. 2006;68(2):352-6.

35. Siami P, Roehrborn CG, Barkin J, Damiao R, Wyczolkowski M, Duggan $\mathrm{A}$, et al. Combination therapy with dutasteride and tamsulosin in men with moderate-to-severe benign prostatic hyperplasia and prostate enlargement: the CombAT (Combination of Avodart and Tamsulosin) trial rationale and study design. Contemp Clin Trials. 2007;28(6):770-9.

36. Ozden C, Ozdal OL, Urgancioglu G, Koyuncu H, Gokkaya S, Memis A. The correlation between metabolic syndrome and prostatic growth in patients with benign prostatic hyperplasia. Eur Urol. 2007;51(1):199-203.

37. Benjamin RM, Yanovski SZ, Simons-Morton DG. Can primary care physician-driven community programs address the obesity epidemic among high-risk populations? JAMA Intern Med. 2013;173(19):1778-9.

38. Freedland SJ, Platz EA, Presti JCJ, Aronson WJ, Amling CL, Kane CJ, et al. Obesity, serum prostate specific antigen and prostate size: implications for prostate cancer detection. J Urol. 2006;175(2):500-4.

39. Lee S, Min HG, Choi SH, Kim YJ, Oh SW, Kim YJ, et al. Central obesity as a risk factor for prostatic hyperplasia. Obesity. 2006;14(1):172-9.

40. Muller RL, Gerber L, Moreira DM, Andriole G Jr, Hamilton RJ, Fleshner $\mathrm{N}$, et al. Obesity is associated with increased prostate growth and attenuated prostate volume reduction by dutasteride. Eur Urol. 2013;63(6):1115-21.

41. Sarma AV, Jaffe CA, Schottenfeld D, Dunn R, Montie JE, Cooney KA, et al. Insulin-like growth factor-1, insulin-like growth factor binding protein-3, and body mass index: clinical correlates of prostate volume among Black men. Urology. 2002;59(3):362-7.

42. Xie LP, Bai Y, Zhang $X Z$, Zheng $X Y$, Yao KS, Xu L, et al. Obesity and benign prostatic enlargement: a large observational study in China. Urology. 2007:69(4):680-4

43. Freedland SJ, Platz EA. Obesity and prostate cancer: making sense out of apparently conflicting data. Epidemiol Rev. 2007;29(1):88-97.

44. Skolarus TA, Wolin KY, Grubb RL. The effect of body mass index on PSA levels and the development, screening and treatment of prostate cancer. Nat Clin Pract Urol. 2007:4(11):605-14.

45. Yang HJ, Doo SW, Yang WJ, Song YS. Which obesity index best correlates with prostate volume, prostate-specific antigen, and lower urinary tract symptoms? Urology. 2012;80(1):187-90.

46. Banez LL, Hamilton RJ, Partin AW, Vollmer RT, Sun L, Rodriguez C, et al. Obesity-related plasma hemodilution and PSA concentration among men with prostate cancer. JAMA. 2007;298(19):2275-80. 
47. Burke JP, Rhodes T, Jacobson DJ, McGree ME, Roberts RO, Girman CJ, et al. Association of anthropometric measures with the presence and progression of benign prostatic hyperplasia. Am J Emidemiol. 2006;164(1):41-6.

48. Parsons JK, Schenk JM, Arnold KB, Messer K, Till C, Thompson IM, et al. Finasteride reduces the risk of incident clinical benign prostatic hyperplasia. Eur Urol. 2012;62(2):234-41.

49. Norgan NG, Cameron N. The accuracy of body weight and height recall in middle-aged men. Int J Obes Relat Metab Disord. 2000;24(12):1695-8.
50. Lennon H, Sperrin M, Badrick E, Renehan AG. The obesity paradox in cancer: a review. Curr Oncol Rep. 2016;18(9):56.

\section{Publisher's Note}

Springer Nature remains neutral with regard to jurisdictional claims in published maps and institutional affiliations.
Ready to submit your research? Choose BMC and benefit from:

- fast, convenient online submission

- thorough peer review by experienced researchers in your field

- rapid publication on acceptance

- support for research data, including large and complex data types

- gold Open Access which fosters wider collaboration and increased citations

- maximum visibility for your research: over $100 \mathrm{M}$ website views per year

At BMC, research is always in progress.

Learn more biomedcentral.com/submissions 